\title{
Design of Urban Safety Management Information System Based on GIS
}

\author{
Jian-Jun Gao \\ School of surveying and land information, \\ engineering ,Henan Polytechnic University, \\ Jiaozuo, China \\ E-mail: gaohappy9@163.com
}

\author{
You-Liang Wang \\ School of emergency management, \\ Henan Polytechnic University, \\ Jiaozuo, China \\ E-mail: ylwang@hpu.edu.cn
}

\begin{abstract}
With analysis of the development of domestic and foreign city safety management information system, the need of the database of city safety management information system were analyzed, which was combined with the characteristics of China's safety management system. This paper tried to design the emergency system database, then the specific process of establishing City Public Security database based on the GIS(Geography Information System) were introduced. Thus a effective and feasible way of establishing the city public safety database were Provided.
\end{abstract}

Keywords-urban safety management; information system; Geography Information System

\section{INTRODUCTION}

With the use of big data and grid technology, public safety in the city are ensured and the normal operation of the city and people's daily life can't be interfered, which is more economical, scientific and feasible choice. Comprehensive, accurate, real-time grasp the dynamic, various types of risk prevention would be put forward in advance, as a result , unexpected events and accidents are controlled. After crisis events information sharing and coordination can be achieved. With the full integration of human and technology, the city emergency management and community become more wisdom, more efficient, and more secure.

Major sports activities or holiday gatherings often happened in Large city, regional hot spots is very easy to cause overcrowded accidents, the big data and the use of spatial technology should be strengthened. With the enhance of city function and expansion of the scope of city, city management information becomes perplexing and exits in the form of network, which needs a powerful information management system to manage the huge amount of data with topological relations, spatial information and attribute information. What's more, it's necessary to propose accurate analysis, identification, risk assessment and timely warning. Therefore, according to the ideas and methods of digital city, management system of city safety with full function should be established based on GIS(Geography Information System).[1]

\section{FUNCTIONAL REQUIREMENT}

In the information age, the government is facing increasingly important issue of the management and operation of a city: how to improve the response ability to deal with emergencies, how to integrate the other city command center into multiple functions, and how to use the existing resources. with Specifically, before the public emergencies happened, emergency management system should be able to work effectively, not only need the city infrastructure management system resources, but also need to rely on advanced information technology. Many sectors, such as accessing public information, processing information, querying and exporting information, should be included, which could further support plans implementation and emergency plans launching with the help of space information.

In summary, Functions of urban safety management information system should include the following:

\section{A. Integration And Management of Basic Information}

Urban managers need to collect, edit and manage the city's basic information to facilitate their management, and they also should provide systematic support for the storage and management of urban geographic information and emergency safety information.

\section{B. Releasing Urban Safety Information Based Network Environment}

It's necessary to develop, integrate and utilize all kinds of city information resources to improve the level of city public facilities and enhance city public service capacity, which can provide timely, interactive and efficient information services to residents, enterprises and society. For the purpose of realizing the perception of wisdom, modeling, analysis and integration, urban safety information should be released on Network Environment in real time.

\section{Decision Making Based On Spatial Information}

In the urban safety management information system, the urban resources, bearing capacity and their distribution density should be counted, which are based on spatial information. It can show the results of statistical analysis, such as statistical chart, numerical classification map. Emergency decision support for city planning, emergency rescue, disaster prediction and early warning can be given.

\section{SYSTEM DESIGNS}

In the design and development of the system, considering the characteristics of the urban safety information system itself and the actual needs of users, it's necessary to follow the principles of standardization and realize the exchange and sharing of urban information. 
In view of the GIS technology is used in Chinese, many users know little of the GIS system. During the design, using an intuitive graphical interface window, users can operate simply. The system should have fault tolerance and strong safety, also it should have the extendibility, for example, the extendibility of the attribute encoding and the software design module. It's necessary to have a complete data update mechanism, because data updating is the life of a information system, otherwise it will become a "dead" system.

\section{A. Architectural Design}

The characteristics of urban public emergencies itself and the environment determine the complexity of city safety management system. As the overall response system of city public emergencies, there should be energy, material and information exchange between urban emergency management system and other places, such as other provinces, city, country and even the world. The emergency system should be divided into traffic subsystem, communication subsystem, public engineering subsystem, fire control subsystem, intelligence and logistics scheduling subsystem, resource subsystem, health and medical rescue system and other subsystems. These subsystems have their subsystems and components of their own, among which have a mutual relationship, forming a huge network multi-level system.

\section{B. Data Organization}

In the database management system, it's key link for the design of the database how to organize, storage and manage the various data according to certain structure, which can improve the system efficiency of information query and processing. In order to facilitate the management and application development, data is divided into different subsets of the database system, according to the basic elements of the city attributes. Here three parts are included, which are spatial database, attribute database and multimedia database.

1) Organization and management of spatial data:Urban emergency management system is built on a large number of urban data, so the first step in the development of contingency planning is to collect and analyze a large number of spatial data at different scales.

The city is relatively concentrated area of the human economic activity, which has more human transformation. So human geography is the main part of city geographical content, which contains more residents, road network, communications equipment, industrial and agricultural facilities, economic cultural and administrative signs and other social economic factors. There are many kinds of city geographical elements, whose instances number is large. So the encoding work is also very complex and it's necessary to have a certain standard to regulate it. Through the standard encoding of the geographical elements, can geographical elements unite in space positioning system scientifically, which is convenient to retrieve and comprehensively analyze data. This actually precedes the establishment of city geographic information system.
City fundamental Geographic Elements are made up of point features, linear elements and areal elements. These elements has been divided into vector data and attribute data stored in the data storing. Vector data represent geometric coordinate information, and attribute data represent physical meaning of elements. Different basic geographic data using hierarchical storage, in which each layer includes a kind of information of a whole map. All elements of map are stored according to the point, line and surface layer. Each layer of information is classified encoding in strict accordance with the classification of data encoding system Standard(as shown in TableI, Table II and Table III).

TABLE I. URBAN GEOGRAPHICALELEMENTS

\begin{tabular}{|c|c|c|c|}
\hline \multicolumn{3}{|c|}{ Urban geographical elements encoding } \\
\hline $\begin{array}{c}\text { Element geometry } \\
\text { type code }\end{array}$ & $\begin{array}{c}\text { Element } \\
\text { class code }\end{array}$ & Location code & $\begin{array}{c}\text { Element } \\
\text { instance } \\
\text { number }\end{array}$ \\
\hline
\end{tabular}

TABLE II. BASIC STRUCTURE OF ROAD INTERSECTION ENCODING

\begin{tabular}{|c|c|c|c|}
\hline \multicolumn{3}{|c|}{ Road intersection encoding } \\
\hline $\begin{array}{c}\text { Element geometry } \\
\text { type code }\end{array}$ & $\begin{array}{c}\text { Element } \\
\text { class code }\end{array}$ & Location code & $\begin{array}{c}\text { Road } \\
\text { intersection } \\
\text { number }\end{array}$ \\
\hline
\end{tabular}

TABLE III.

BASIC STRUCTURE OF BLOCK ENCODING

\begin{tabular}{|c|c|c|c|}
\hline \multicolumn{3}{|c|}{ Block encoding } \\
\hline $\begin{array}{c}\text { Element geometry } \\
\text { type code }\end{array}$ & $\begin{array}{c}\text { Element } \\
\text { class code }\end{array}$ & Location code & $\begin{array}{c}\text { Block } \\
\text { number }\end{array}$ \\
\hline
\end{tabular}

Examples of Basic geographic data hierarchy and file naming are shown in TableIV.

TABLE IV. BASIC GEOGRAPHIC DATA HIERARCHY (PART)

\begin{tabular}{|c|c|c|}
\hline $\begin{array}{c}\text { Data layer } \\
\text { name }\end{array}$ & Data layer description & $\begin{array}{c}\text { Data } \\
\text { types }\end{array}$ \\
\hline $\begin{array}{c}\text { Administrative } \\
\text { boundary }\end{array}$ & Various boundaries & Line \\
\hline settlement & residential land & Areal \\
\hline green area & green area & Areal \\
\hline $\begin{array}{c}\text { Transportation } \\
\text { hub }\end{array}$ & Cus station & Point \\
\hline Road & Surface drainage system & Line \\
\hline Lake & Areal \\
\hline River & $\begin{array}{c}\text { Double line and double line channel } \\
\text { recreational facilities }\end{array}$ & Areal \\
\hline $\begin{array}{c}\text { Entertainment } \\
\text { shopping }\end{array}$ & $\begin{array}{c}\text { Medical, posts and } \\
\text { other facilities }\end{array}$ & Point \\
\hline $\begin{array}{c}\text { public service } \\
\text { elecommunications, fire stations and }\end{array}$ & Point \\
\hline
\end{tabular}

2) Organization and management of attribute data: The attribute data are also known as statistical data. The attribute data are detailed descriptions of the target space features, which contains a specific description of the target type and a description of the target. The target type is required for each spatial object, so some GIS software records it directly into 
spatial data, which facilitates signifying and hierarchically display data.

Thematic database is the subject of city safety management system, and it is the core part of application system which users are interested in. In order to facilitate the management of the system, the system organizes thematic data into different layers using the hierarchical database technology, which involves in geographic information. Each layer uses thematic symbols and corresponds to different data sources, that is, each layer is matched with the spatial graph and attribute data.

There are two main types of input mode of the system attribute data, one is to input some simple information directly on the basis of graphics; the other is to pre-establish attribute table to input attributes, or to import properties from other statistical database, then connect with graphics data automatically according to the key words. Considering the characteristics of this system, the small desktop relational database management system are used, which has relatively simple structure and data modification and updating more convenient(as shown in Table V).

TABLE V.PUBLIC FACILITY ATTRIBUTE TABLE

\begin{tabular}{|c|c|c|c|c|}
\hline $\begin{array}{c}\text { Attribute } \\
\text { number }\end{array}$ & $\begin{array}{c}\text { Attribute } \\
\text { name }\end{array}$ & $\begin{array}{c}\text { Data } \\
\text { type }\end{array}$ & Length & remark \\
\hline 1 & $\begin{array}{c}\text { fire station } \\
\text { code (ID) }\end{array}$ & Int & & \\
\hline 2 & $\begin{array}{c}\text { fire station } \\
\text { name }\end{array}$ & Char & 24 & \\
\hline 3 & $\begin{array}{c}\text { Information } \\
\text { introduction }\end{array}$ & Char & 255 & \\
\hline 4 & Address & Char & 36 & \\
\hline 5 & Phone & Char & 24 & \\
\hline
\end{tabular}

3) Organization and management of multimedia data: Deep integration of video resources can build threedimensional city security system and improve the covering density and quality of construction of the city video monitoring system, which can promote the building of the city three-dimensional prevention and control system. The application of video resource integration can enhance the visualization of safe city level, then implement effective integration of urban management resources among traffic, bank, school, and districts. So by breaking the "video island", the sharing of video resources within a certain range are realized. Thus the video visualization applications are expanded gradually and can provide a good foundation for the deep application of video data in the peaceful city.

Multimedia data of city security management information system include texts, pictures, audio and video data which reflect city information and infrastructure related to services and public management, such as hotels, entertainment, shopping and other information. In this system, a relational database is used to establish a field name, in which the access path of multimedia data is stored. While the actual multimedia data are stored and managed in the form of document, which can be invoked in the relevant module to play multimedia data.

\section{Functional Module}

Using GIS tools and development platform and some auxiliary development software, the system realize the function of system design based on B/S mode. Firstly, through logical analysis and functional analysis, the system is divided into several function modules, and then the specific functions of each module is refined, the module is integrated lastly according to the agreed interface. It uses the modular structure for the development of a module of a specific function, if there is a new model, only the corresponding module need to be changed. In other words, the information system can be updated and extended.

System function modules realized the function of the public information query, map operation, line optimization, message management, spatial analysis and auxiliary decision-making.

1) Public information inquiry: This function module can inquiry information according to a keyword. If the user wants to understand an object, he can enter the object name, code or combined conditions for range queries. Fuzzy queries are supported in order to facilitate user's query.

The system classified information according to the regional level of city, so managers just need to select the appropriate category, which can show the basic information of the class. If users want to understand a specific information in detail, he can click on the corresponding super link to display location information. If only partial information wants to be known, such as the general name the area, district belonging to etc, the information can also be obtained in the method of fuzzy query.

2) Map operation: This module is a set of map operation function provided for the users to browse maps conveniently, by which a simple operation on the map can be realized, including the full-size display, amplification, narrow, roaming, object selection, Hawkeye navigation of the map. For example, target spots can be selected by clicking directly on the map, and by delineating a range of a map in the window, users can select public facilities in the range. These functions can be used to achieve map view or quickly locate the area or specific targets which users are interested in.

3) Spatial analysis and assistant decision: The system possesses a powerful analysis function of spatial geographic information, such as buffer analysis, hierarchy analysis method and so on. The system can calculate the distance between two objects in a map. Aided with the database, the recent information of the city can be collected, through a series of professional decision-making model, decisionmaking information such as safety information forecast and emergency management are provided for users.

4) Traffic optimization: GIS technology can help to Calculate the geographic distribution of the passengers and Calculate the population near the bus lines and stations, which can give a reasonable route planning to improve the city traffic management based on travel traffic, road traffic 
conditions and other factors. It can provide scientific basis for government decision-making. According to the actual needs, the electronic map system controls geographical elements more flexibly with traffic planning elements layered.

5) Message management: Administrators can use "information feedback" and "management" functions label in the message board, in which administrators not only can leave a message or reply, but also can revise or delete message by a special user name and password. "management personnel" label is designed for city management, notices and documents can be issued within the Department and uploading and downloading of various data file are provided.

\section{CONCLUSION}

With the rapid development of economic construction, city urbanization, the number of the city and the city population increased rapidly. With the highly populated city population, city construction and city traffic, and the rapid development of city economy, the city itself has faced many problems.

The author hopes to promote the construction of city safety management information system to improve the social public security management. Big data expand the huge space for social governance, also have provided the infinite possibility. Only by establishing a large data public security concept can the public security work has the big data as its wings and meet the needs of the times and the demands of the people.

\section{REFERENCES}

[1] Xiangtang and Liuxiong, Research on the application of GIS technology in urban planning management information system[J], Digital Technology and Application,Vol 8, 2014.

[2] Yanlei and Yanqijiao, GIS technology and its application in city fire control communication command system [J], Heilongjiang Science and Technology Information,Vol 1, 2010.

[3] Chenglin, Wangfahui and Xiuchunliang, Analysis of the service area of Changchun city's large supermarket based on GIS [J], economic geography ,Vol 4,2014.

[4] Shijie and Wangpengcheng, Research on urban planning management information system based on GIS [J], Chongqing architecture,Vol 7,2011 .

[5] J. Blauth, I. Poretti, M. De Amicis and S. Sterlacchini, "Database of Geo-Hydrological Disaster for Civil Protec- tion Purposes,” Natural Hazard, Vol. 60, No. 3, 2012, pp. 1065-1083.

[6] M. Konecny, S. Zlatanova and T. L. Bandrova, "Geogra- phic Information and Cartography for Risk and Crisis Management," Springer, Berlin, 2010.

[7] Ivan Frigerio, Stefano Roverato and Mattia De Amicis, A Proposal for a Geospatial Database to Support Emergency Management, Journal of Geographic Information System, Vol 5, 2013, 396-403.

[8] Rice, M., Paez, F., Mulhollen, A., Shore, B. and Caldwell, D. (2012) Crowdsourced Geospatial Data: A Report on the Emerging Phenomena of Crowdsourced and User-Generated Geospatial Data. Annual. George Mason University, Fairfax. http://www.dtic.mil/dtic/tr/fulltext/u2/a576607.pdf 